\title{
Severe cerebral degeneration associated with primary hepatic carcinoma
}

\author{
E. R. BICKERSTAFF, E. A. ElABUtE, AND A. L. WOOLF \\ From the Midland Centre for Neurosurgery and Neurology, Smethwick
}

The case reported below came under our observation 10 years ago. It appeared to be unique in that extremely severe degeneration of the brain, of the type encountered in hepatic failure, and leading to the patient's death, was associated with a primary carcinoma of the liver in a young woman who had lived only in Britain. Since we made our observations no further association of this type has been reported, nor has there been any description of such extensive hepatocerebral degeneration.

\section{CLINICAL HISTORY}

A woman aged 22 was admitted to the Midland Centre for Neurosurgery on 10 May 1956 (case no. 56/228). Six weeks before admission she had developed depression, anorexia, nausea and abdominal pain, followed by repeated vomiting. During the night of 26 April 1956 she became increasingly restless and this restlessness progressed to outbursts of violent behaviour, followed by drowsiness. By the next morning she was confused, had difficulty in speaking, and later lapsed into semi-consciousness and was admitted to Dudley Road Hospital, Birmingham, in deep coma. Examination at that time showed the fundi to be normal, the pupils dilated but reacting, the limbs flaccid but the tendon reflexes preserved. The abdomen was distended. The blood pressure was $170 / 110 \mathrm{~mm}$.Hg. Investigations showed a blood urea level of $35 \mathrm{mg}$. per $100 \mathrm{ml}$. and blood sugar $99 \mathrm{mg}$. per $100 \mathrm{ml}$. Cerebrospinal fluid, under normal pressure, was clear and colourless with normal cytology and chemistry. Urinary and cerebrospinal fluid barbiturate levels were not significant.

Over the next three days she recovered consciousness, complained of pain beneath the left lower ribs on deep inspiration, and maintained a pulse rate of 120 . On 8 May she again lapsed into coma, again with no signs suggestive of a localized cerebral lesion. The blood sugar measurement was repeated and stood at $148 \mathrm{mg}$. per $100 \mathrm{ml}$. A radiograph of the chest showed elevation of the left diaphragm. Because of the possibility that a relapsing coma might be caused by a mid-line intraventricular obstructive lesion she was transferred to the Midland Centre for Neurosurgery and on 14 May Mr. R. Campbell Connolly carried out Myodil ventriculography through a left frontal burr hole. Intracranial pressure was low; the ventriculogram showed no abnormality and the ventricular fluid was normal.
Consciousness did not return, and the patient died on 16 May seven weeks after the onset of symptoms. At no stage had there been any suggestion of anoxia.

\section{POST-MORTEM EXAMINATION}

The body was that of a normally developed, thin girl. The brain and spinal cord were removed and fixed undissected, no external abnormality being observed. The peritoneum was studded with small pearly tumours some of which were haemorrhagic. They were most numerous in the pelvis where many were confluent. The cervix was reddened but there was no tumour in the uterus, vagina, or bladder. There was a purulent cystitis and blurring of the cortico-medullary pattern of both kidneys. Large sphericat masses of haemorrhagic tumour were present along the aorta, in the lesser omentum, and in the lymph nodes ab the bifurcation of the trachea. The lungs were normad apart from an ill-defined mass in the left lower lobe and adherent to the diaphragm. On sectioning the bifurca tion lymph nodes, the largest of which measured $4 \times 2.5$ $\times 2 \mathrm{~cm}$., the cut surface was seen to consist of the same cream-coloured fleshy tissue as that seen in the left lobe of the liver. The liver weighed $2,088 \mathrm{~g}$. There were several small masses and one large mass in the left lobe which was adherent to the diaphragm. On sectioning through the large mass it was seen to have a central spherical portion $4 \times 3 \mathrm{~cm}$. on cross section with a fibrous capsule up to $0.2 \mathrm{~cm}$. in thickness but broken in one place where it communicated with cream-coloured fleshy tissue divided into course lobules by fibrous trabeculae. The central mass itself appeared to have a fibrous tissue core, the remainder resembling the surrounding cream-coloured fleshy tissue but with slightly more trabeculation. Towards its periphery and for half its circumference the tissue was greenish in colour. The rest of the liver showed accentuation of the lobular pattern. There was recent ante-mortem thrombus in the inferior vena cava, iliac veins, and cavernous sinuses. There was a cystic softening in the pituitary.

DISSECTION OF THE BRAIN AFTER FIXATION The brain, which weighed 1,285 g., showed no abnormality on external examination except for tentorial grooving of the right uncus. There were no metastases. The vessels at the base of the brain appeared normal. On coronal section the globus pallidus on each side appeared paler than normal and that on the right side showed a less distinct demarcation of the outer and inner portions than on the left. The sub- 
stantia nigra appeared considerably paler than normal on both sides.

\section{HISTOLOGY}

LIVER The central mass was composed of cells with bulky eosinophil cytoplasm and an irregular but sharply demarcated outline with large nuclei of moderate chromatin content (Fig. 1). Most of the nuclei were circular but occasional giant nuclei with a more irregular outline and a high chromatin content were also seen. The cells were separated from one another by a large amount of fibrous tissue. The mass was surrounded by a capsule of dense fibrous tissue in which were situated groups of apparently normal liver cells but lacking the normal lobular arrangement There were also scattered bile canaliculi and diffuse and more focal lymphocytic infiltration. Immediately outside the capsule the cells resembled more closely normal liver cells but they were much larger and had larger vesicular nuclei with prominent nucleoli. There was less fibrous tissue in these areas. The part of the liver which had a more macroscopically normal appearance histologically showed a centrilobular loss of liver cells with enlarged sinusoids and an increase in fibrous tissue around the portal tracts. Perisinusoidal fibrosis extended throughout the lobule.

LYMPH NODES AT BIFURCATION OF TRACHEA Lymphoid tissue was confined to a thin rim just under the fibrous capsule of the gland; the rest of the gland was occupied by cells closely resembling normal liver cells except for their large nuclei with poor chromatin content and prominent and often very large eosinophil nucleoli. These cells showed no lobular arrangement, but there were scattered areas of lymphocytic infiltration amongst them.

BRAIN Blocks were taken from the right and left frontal lobes, from the region of the fissure of Rolando on both

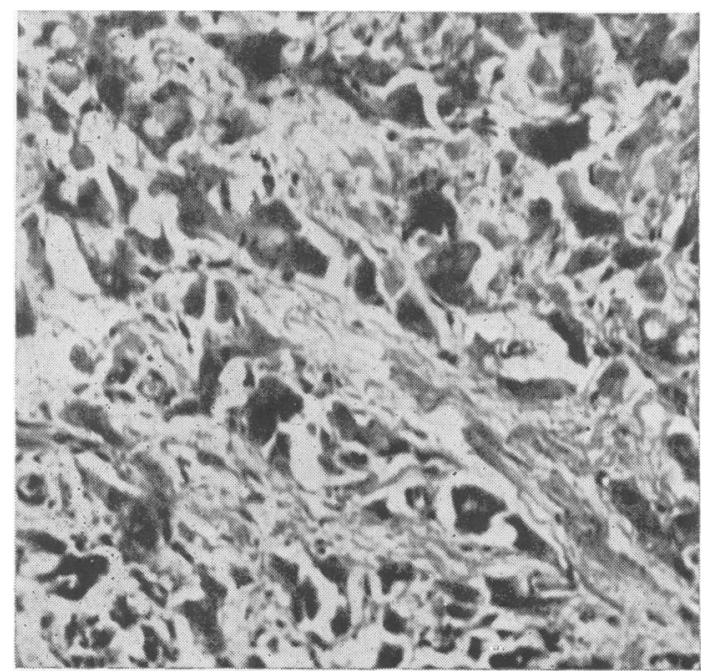

FIG. 1. Liver showing hepatocellular carcinoma. Haematoxylin and eosin $\times 104$. sides, from the right and left temporal and occipital lobes and the basal ganglia, mid-brain, pons and medulla, the right and left lateral lobes of the cerebellum and the eighth cervical, fourth thoracic, and first lumbar segments of the spinal cord.

Almost the whole of both cerebral hemispheres showed a loss of nerve cells from layers II to IV with proliferation of astrocytes with large pale nuclei forming themselves into groups (Figs. 2-3). Under high magnification these cells showed no cytoplasm but under lower magnification each astrocytic nucleus was seen to be surrounded by a feathery increased staining (Nissl) of the background, probably corresponding to the processes of the astrocytes. There was also an increase in the microglia in the form of rod cells. The above changes were seen in parts of the right superior and inferior temporal gyri and affected the whole of the right middle temporal gyrus. Parts of most of the convolutions of both oecipital lobes were affected but the calcarine gyri were completely spared. Every gyrus of the left temporal lobe was affected and around the sulci all layers of the cortex showed total loss of nerve cells. In the left frontal lobe the changes in the cortex were mainly confined to the areas surrounding the sulci. The geniculate bodies were normal. In the region of the fissure of Rolando, and including the precentral convolution, the cortical changes were also as described above. Both Ammon's horns showed severe loss of nerve cells in Sommer's sector and the subiculum with proliferation of the endothelium of the vessels microglia and astrocytes (Figs. 4 and 5). In the left putamen there were Alzheimer II glial nuclei with very little chromatin. There were large, astrocytes in the left global pallidus and amygdaloid nucleus. The left caudate nucleus was normal. In the medulla there was marked perivascular infiltration in the anterior median fissure with mostly karyorrhectic leucocytes. The olives and cranial nerve nuclei were not affected. In the spinal cord astrocytes with bulky cytoplasm and large, slightly hypochromatic nuclei were present in the grey matter of the anterior horns and in the white matter of the posterior columns adjacent to the posterior columns.

\section{DISCUSSION}

The occurrence of cirrhosis of the liver in a young woman in the absence of alcoholism and without any history suggestive of hepatitis is itself unusual, but the development of a primary hepatocellular carcinoma leading to liver failure and a more severe hepato-cerebral degeneration than any previously reported is thought to justify the report of this single case. Beyond the description of the findings there is, however, little to add except to draw attention to the remarkable restriction of the cerebral degeneration to the outer layers of the cerebral cortex, especially around the sulci, and the Ammon's horn.

Histological changes in the brain in asssociation with liver disease other than in Wilson's disease were first described by Insabato (1924) and Pollak (1927). These were confirmed by Cammermeyer (1947) but 


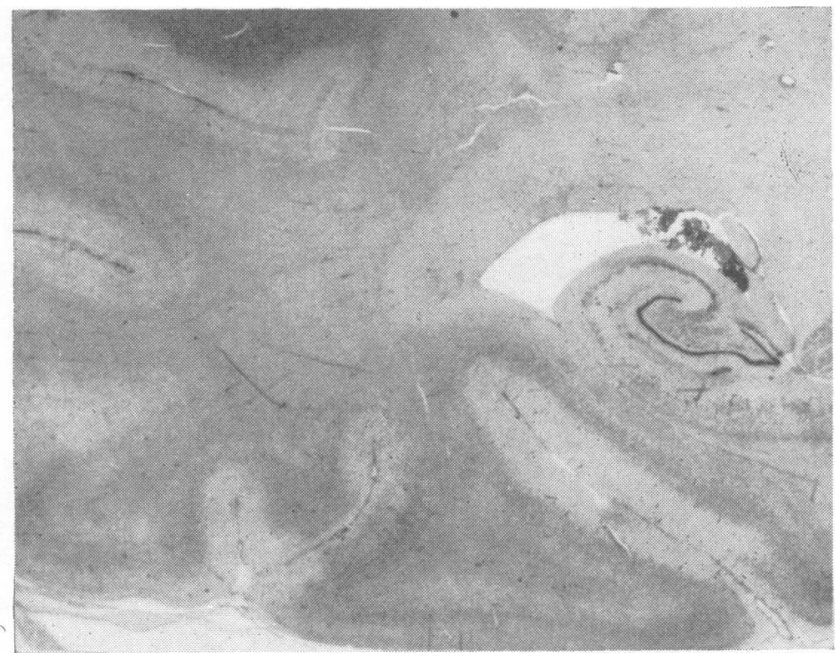

FIG. 2.

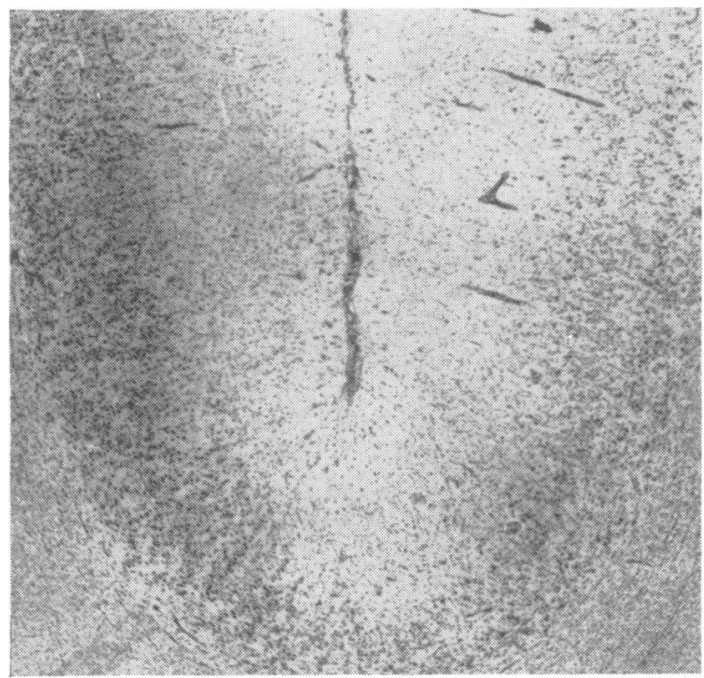

FIG. 3 .

FIG. 2. Left temporal lobe showing pallor of superficial layers of cortex more severe within sulci. Nissl $\times 4$.

FIG. 3. Left middle and inferior temporal gyri showing loss of nerve cells from superficial layers. Nissl $\times 16$.

FIG. 4. Ammon's horn, $h_{3}$ sector. Normal appearance. Nissl $\times 104$.

FIG. 5. Ammon's horn, Sommer's sector, showing total loss of nerve cells with glial proliferation. Nissl $\times 104$.

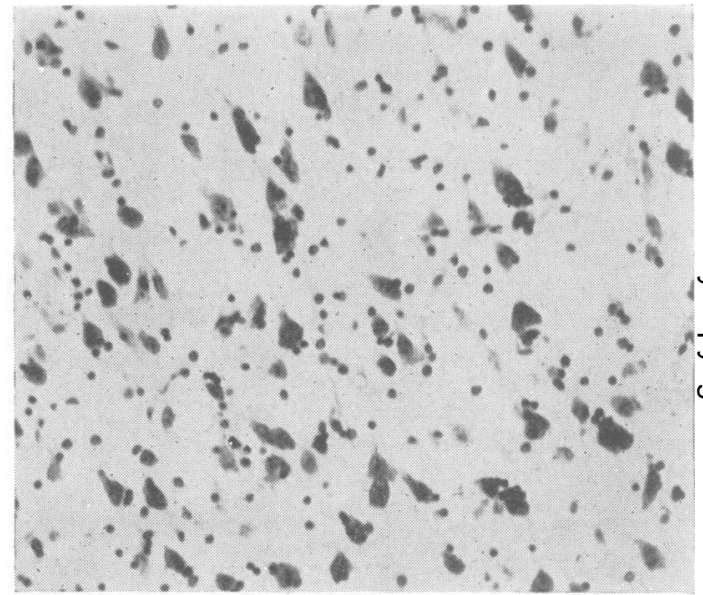

FIG. 4.

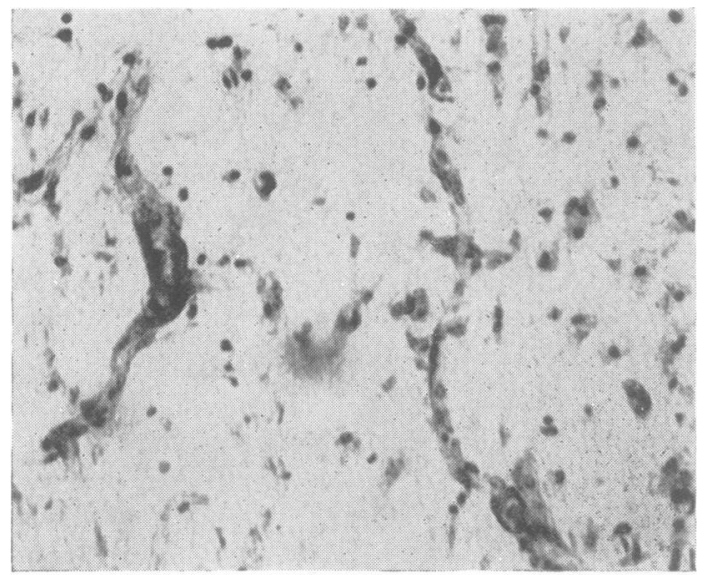

FIG. 5 . 
the most comprehensive report is that of Adams and Foley (1953). They described 60 cases but in none of them was the brain as severely degenerated as in our case. Indeed in only one case was nerve cell degeneration at all pronounced. In this case, in which death occurred on the 49th day of hepatic coma, all the nerve cells in layers II and III of several of the orbital frontal convolutions had disappeared and were replaced by plump astrocytes and pleomorphic microgliocytes. Thus the cerebral changes in their case, though somewhat less severe and extensive, closely resembled ours in their nature and distribution.

The clinical importance of this case stems from the fact that when faced by the problem of relapsing coma in a young adult, free from any history of past or present liver disease or exposure to hepatotoxic agents, the possibility of hepato-cerebral degeneration may not even be considered, and certainly a primary hepatic carcinoma is so rare in this country that it may not be suspected. Such a diagnosis will only be made in life if the clinician is aware that such lesions may occur without giving any hint of their presence other than by disturbances of consciousness, and it seems justifiable, in obscure cases of relapsing coma, to include full investigation of hepatic function, including adequate biopsy, even when there is no reason to suspect liver disease.

Pathologically the interest centres on the remarkably severe degeneration of the cerebral cortical nerve cells. Its restriction to the superficial layers suggests that if a noxious agent were responsible it might have reached the cortex through the cerebrospinal fluid.

Our thanks are due to Dr. Kenneth May for allowing us to refer to notes taken while the patient was at Dudley Road Hospital and to Mr. G. Gasser for photographic assistance.

\section{REFERENCES}

Adams, R. D., and Foley, J. M (1953.) The neurological disorder associated with liver disease. Res. Publ. Ass. nerv. ment. Dis., 32, 198-237.

Insabato, L. (1924.) Alcune osservazioni sull' etiopatogenesi delle degenerazioni epatolenticolaris. l'alcoolismo come causa di degenerczione epatonevrologiea, Arch. gen. Neurol. Psichiat., 4/5, 14-22.

Pollak, E. (1927.) Zur Frage der Beziehungen von Leber und Gehirner krankungen. Arb. neurol. Inst. Univ. Wien, 30, 148-162.

Cammermeyer, J. (1947.) Deposition of iron in paraventricular areas of the human brain in hemochromatosis. J. Neuropath. exp. Neurol., 6, 111-127. 